\title{
LIXIVIAÇÃO DE LAMAS EM ESCALA LABORATORIAL PARA REMOÇÃO DO ÓXIDO DE ZINCO*
}

Tiago Silva Costa ${ }^{1}$ Janaina Oliveira Maia²

\section{Resumo}

O processo que envolve soluções aquosas para remoção do metal de valor de uma grande massa de ganga, com um beneficiamento mínimo, é denominado Lixiviação. A especificidade do agente lixiviante empregado define a capacidade de tratar soluções com baixos teores do metal de interesse e o sucesso do processo. A lama da aciaria, recolhida no sistema de limpeza dos gases oriundos do convertedor LD, e a lama da eletrogalvanização, gerada após a neutralização da solução de zinco contaminada com ferro, são resíduos sólidos gerados nas usinas siderúrgicas com potencial de serem reutilizados ou reciclados. A fim de se remover o óxido de zinco presente nas lamas, amostras foram coletadas e preparadas para sofrerem 0 processo de lixiviação em escala laboratorial usando soluções de hidróxido de sódio $(\mathrm{NaOH})$ e ácido sulfúrico $\left(\mathrm{H}_{2} \mathrm{SO}_{4}\right)$. Os resultados obtidos nas análises mostraram que é possível remover óxido de zinco através da lixiviação das lamas.

Palavras-chave: Lixiviação; Zinco; Lama da aciaria; Lama da eletrogalvanização.

\section{SLUDGE LEACHING IN LABORATORY SCALE FOR ZINC OXIDE REMOVAL Abstract}

The process involves aqueous solution for removing valued metal from a large mass of sludge, with minimal processing, is called leaching. The specificity of the leaching agent used defines the ability to treat solutions with low levels of the metal of interest and the success of the process. The sludge from the melt shop, collected in the gas cleaning system from the LD converter, and the sludge from the electrogalvanizing plant, generated after the neutralization of contaminated zinc solution with iron, are solid waste generated in steel plants with potential to be reused or recycled. In order to remove the zinc oxide present in the sludge, samples were collected and prepared for undergoing the leaching process on a laboratory scale using sodium hydroxide $(\mathrm{NaOH})$ and sulfuric acid $\left(\mathrm{H}_{2} \mathrm{SO}_{4}\right)$ solutions. The results of the analysis showed that zinc oxide can be removed by leaching the sludge.

Keywords: Leaching; Zinc; Sludge of melt shop; Sludge of electrogalvanizing.

1 Técnico Metalurgista, Graduando em Engenharia Metalúrgica, Centro Universitário do Leste de Minas - UNILESTE MG, Associado ABM Júnior, Coronel Fabriciano, Minas Gerais, Brasil.

2 Técnica em Química, Graduanda em Engenharia Metalúrgica, Centro Universitário do Leste de Minas - UNILESTE MG, Coronel Fabriciano, Minas Gerais, Brasil. 


\section{INTRODUÇÃO}

Lixiviação é o processo dissolução do mineral pela água ou por uma solução aquosa do agente lixiviante. Tem como objetivo a remoção do metal de valor da massa de ganga com o beneficiamento mínimo do minério [1]. Existem diversos métodos de lixiviação e a escolha de um deles depende de fatores como a granulometria do minério, a taxa de produção, o custo do processo, a composição do mineral e as técnicas subsequentes necessárias.

Para que o processo seja efetivo, o agente lixiviante usado deve dissolver elementos indesejados e não reagir com a ganga. Esta seletividade se baseia na diferença de concentração de íons, enquanto o metal de valor tem elevada concentração, a ganga possui baixa.

Segundo Araújo [2], durante a conversão de gusa em aço, as partículas de ferro são desprendidas e ejetadas do banho metálico em altas temperaturas, num ambiente fortemente oxidante. Estes particulados são arrastados para o sistema de exaustão de gases onde formam os pós e lamas da aciaria provenientes dos sistemas de despoeiramento dos convertedores [3]. É atrativa a reutilização dessa lama na produção de sínter ou pelotas devido o alto teor de ferro, mas para isso deve-se remover o zinco agregado pela utilização de sucata galvanizada na produção de aço. Durante processo no alto forno, o zinco presente favorece a formação do "cascão" que adere à parede refratária do reator e ocasiona diversos problemas operacionais.

A galvanização é o processo de revestimento de um metal por outro a fim de protegê-lo contra a corrosão ou melhorar sua aparência. Na eletrogalvanização o revestimento das superfícies ocorre por meio da eletrólise, onde o metal a ser revestido funciona como cátodo e o metal que irá revestir a peça funciona como o ânodo. No decorrer do processo de eletrogalvanização, na cuba de zincagem, a solução de zinco é consumida pela deposição nas chapas de aço e ao mesmo tempo contamina-se com ferro, sendo essa retirada e reposta por uma nova solução. A solução contaminada com ferro retirada é neutralizada com cal, formando o decantado de zinco chamado de lama da eletrogalvanização.

Este artigo descreve os métodos utilizados para caracterização das lamas geradas em processos industriais e remoção do óxido de zinco $(\mathrm{ZnO})$.

\section{MATERIAIS E MÉTODOS}

A amostragem foi composta por $3 \mathrm{Kg}$ de lama da aciaria e $3 \mathrm{Kg}$ de lama da eletrogalvanização. Para determinar o teor de umidade as amostras foram colocadas em bandejas, pesadas e encaminhadas para secagem em estufa a $80^{\circ} \mathrm{C}$. Após um período de 36 horas foram retiradas da estufa e pesadas novamente sendo a diferença de massa atribuída ao teor de umidade.

As amostras foram transferidas para uma mesa de quarteamento e divididas em quatro partes iguais, sendo tomadas as duas partes opostas entre si para constituição da nova amostra, conforme item 2.8 da ABNT NBR10007 [5]. O quarteamento foi repetido sucessivas vezes para que obtivessem uma amostra com massa de $1 \mathrm{Kg}$. Através de um moinho de bolas as amostras foram pulverizadas até adquirir granulometria menor que $0,074 \mathrm{~mm}$ e após foram acondicionadas em sacos plásticos com lacre para realização dos próximos ensaios.

A análise da composição química foi realizada por fluorescência de Raios-X, no Espectrômetro de Fluorescência de Raios-X, marca Shimadzu, modelo $800 \mathrm{HS}$, em pastilhas prensadas - figura 1. 


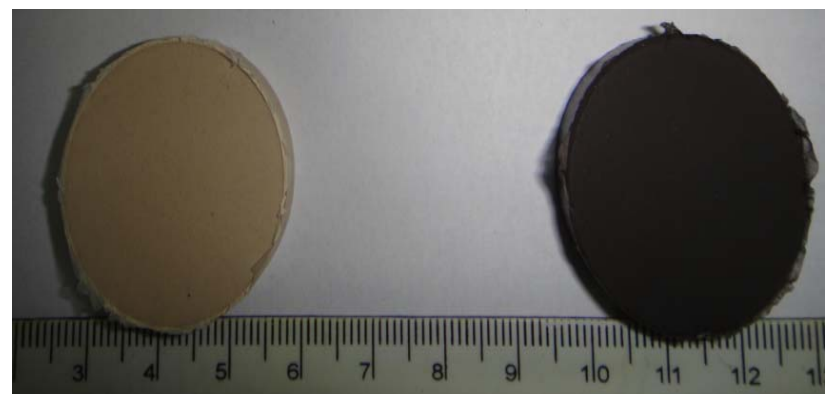

Figura 1. Pastilhas prensadas para determinação da composição qualitativa por EDX (Pastilha clara - lama da eletrogalvanização; Pastilha escura - lama da aciaria)

Os resultados de análise química demonstraram que a lama da eletrogalvanização apresenta maior teor de zinco que a lama da aciaria e, por isso, os ensaios preliminares foram realizados somente nela.

Cinco gramas da amostra foram pesadas e transferidas para um Becker de $600 \mathrm{ml}$ e adicionou-se $20 \mathrm{ml}$ de solução hidróxido de sódio $(\mathrm{NaOH})$ com $20 \%$ de concentração para solubilização da amostra, em seguida $20 \mathrm{ml}$ de solução ácido sulfúrico $\left(\mathrm{H}_{2} \mathrm{SO}_{4}\right)$ foram adicionados para precipitação do zinco conforme equações 1 e 2 .

$$
\begin{gathered}
\mathrm{ZnO}(\mathrm{s})+\mathrm{NaOH}(\mathrm{aq})-\mathrm{Zn}(\mathrm{OH})_{2}(\mathrm{~s})+\mathrm{Na}^{+}(1) \\
\mathrm{Zn}(\mathrm{OH})_{2}(\mathrm{~s})+\mathrm{H}_{2} \mathrm{SO}_{4}-\mathrm{ZnSO}_{4}+2 \mathrm{H}_{2} \mathrm{O}(2)
\end{gathered}
$$

A solução foi colocada em um agitador eletromagnético por 6 horas e permaneceu em repouso por 15 horas. Em seguida as amostras foram filtradas com papel de filtro faixa branca (filtração média) e secas em estufa a $90^{\circ} \mathrm{C}$ por 3 horas. O teor de zinco foi obtido pela diferença de massa na pesagem do resíduo. Este procedimento foi realizado em triplicata.

Após definição da metodologia os ensaios também foram realizados com as amostras de lama da aciaria.

\section{RESULTADOS E DISCUSSÃO}

\subsection{Teor de Umidade}

$\mathrm{Na}$ tabela 1 são apresentados o teor de umidade das amostras. A lama da eletrogalvanização apresentou teor de umidade 8,08 vezes maior que o da lama da aciaria.

Tabela 1. Resultado do teste para determinação da umidade nas amostras

\begin{tabular}{|c|c|c|c|}
\hline Processo gerador & Amostra úmida (g) & Amostra seca (g) & Teor de Umidade (\%) \\
\hline Eletrogalvanização & 703,10 & 356,97 & 49,23 \\
\hline Aciaria & 500,90 & 470,40 & 6,09 \\
\hline
\end{tabular}

\subsection{Composição Química}

Na tabela 2 apresentam-se os resultados das análises de composição química das amostras, obtida via fluorescência de Raios-X. 
Tabela 2. Composição química

\begin{tabular}{|c|c|c|}
\hline \multirow{2}{*}{ Composição química das lamas (\%) } \\
\hline \multirow{2}{*}{ Elemento } & \multicolumn{2}{|c|}{ Processo gerador } \\
\cline { 2 - 3 } & Aciaria & Eletrogalvanização \\
\hline $\mathrm{ZnO}$ & 1,75 & 30,36 \\
\hline $\mathrm{CaO}$ & 12,60 & 13,54 \\
\hline $\mathrm{MgO}$ & 2,44 & 1,44 \\
\hline $\mathrm{Fe}_{2} \mathrm{O}_{3}$ & 79,83 & 1,32 \\
\hline $\mathrm{SiO}_{2}$ & 1,23 & 1,53 \\
\hline $\mathrm{MnO}^{2}$ & 1,18 & 0,07 \\
\hline $\mathrm{P}_{2} \mathrm{O}_{5}$ & 0,42 & 0,63 \\
\hline $\mathrm{K}_{2} \mathrm{O}$ & 0,32 & \\
\hline $\mathrm{SO}_{3}$ & 0,19 & 1,26 \\
\hline $\mathrm{SrO}^{2}$ & 0,04 & 0,15 \\
\hline $\mathrm{Al}_{2} \mathrm{O}_{3}$ & & 0,42 \\
\hline $\mathrm{NiO}_{2 \mathrm{O}}$ & & 0,07 \\
\hline $\mathrm{ZrO}_{2}$ & & 0,01 \\
\hline
\end{tabular}

A amostra de lama da aciaria apresenta elevado teor de $\mathrm{Fe}_{2} \mathrm{O}_{3}$ e baixo teor de $\mathrm{ZnO}$ conforme exposto por Oliveira E Silva [4]. O autor afirma que a lama da aciaria é composta predominantemente por ferro e o teor de $\mathrm{ZnO}$ está associado à utilização de sucata galvanizada nas cargas dos convertedores.

\section{3 Óxido de Zinco Recuperado}

$\mathrm{Na}$ tabela 3 são apresentadas as porcentagens do óxido de zinco $(\mathrm{ZnO})$ recuperado nos processos.

Tabela 3. Porcentagem do óxido de zinco recuperado

\begin{tabular}{|c|c|c|}
\hline \multicolumn{2}{|c|}{ ZnO recuperado (\%) } \\
\hline \multirow{2}{*}{ Análise } & \multicolumn{2}{|c|}{ Processo gerador } \\
\cline { 2 - 3 } & Aciaria & Eletrogalvanização \\
\hline 1 & 4,20 & 24,82 \\
\hline 2 & 3,93 & 23,94 \\
\hline 3 & 3,40 & 24,11 \\
\hline
\end{tabular}


O uso de soluções ácidas para recuperação do óxido de zinco favorece a precipitação de elementos interferentes mais densos que o óxido. Isso explica porque o teor de $\mathrm{ZnO}$ recuperado (tabela 3 ) da lama da aciaria é maior que o teor de $\mathrm{ZnO}$ obtido por análise de Raios-X (tabela 2 ).

\section{CONCLUSÃO}

Os resultados obtidos nas análises mostraram que a lama da eletrogalvanização tem elevado teor de umidade quando comparada com a lama da aciaria. A lama da aciaria é composta predominantemente por ferro e o baixo teor de zinco presente na lama está associado à utilização de sucata galvanizada no convertedor LD. Durante a recuperação do óxido de zinco na lama da aciaria ocorreu precipitação de elementos mais densos aumentando o teor zinco na lama quando comparado com a análise quantitativa. De forma geral, conclui-se que, apesar da elevada umidade e da presença de elementos residuais nas amostras, é possível remover óxido de zinco com a metodologia aplicada.

\section{REFERÊNCIAS}

1 Cezar Heck, Nestor. Metalurgia Extrativa dos Materiais Não-Ferrosos I-A. ENG 06631.

2 Araújo, Luiz Antônio de. Manual de siderurgia - Volume 1 - Produção. Editora Arte \& Ciência, 2007.

3 Vinícius Catarino, Marcos. Estudo da remoção de zinco e de álcalis contidos em lama de aciaria. Escola de Engenharia UFMG, Belo horizonte, 2011.

4 Oliveira E Silva, Emanuel Augusto de. Cinética de Digestão Alcalina da Franklinita na Lama Fina de Aciaria LD. Escola de Engenharia UFMG, Belo horizonte, 2014.

5 Associação Brasileira De Normas Técnicas: NBR 10007:2004. Amostragem de resíduos sólidos. ABNT, Brasil. 